\title{
DEZ ANOS NO AMAZONAS (1897-1907): UM IMAGINÁRIO SOCIAL DA AMAZÔNIA
}

Altaíza Liane Marinho ${ }^{1}$

\section{RESUMO}

O artigo intitulado "Dez. anos no Amazonas (1897-1907): um imaginário social da Amazônia" tem como corpus de análise as narrativas de Alfredo Lustosa Cabral em seu livro "Dez anos no Amazonas (1897-1907): Memória de um sertanejo nordestino emigrado àquelas paragens em fins do século passado”. O objetivo é problematizar a partir das narrativas de Alfredo Lustosa Cabral, que permaneceu dez anos nos seringais da Amazônia, entre 1897 a 1907, propondo uma reinterpretação deste imaginário social da Amazônia, tomando por uso a corrente da Análise do Discurso (AD). Para fundamentar o trabalho aqui desenvolvido, utilizamos os estudos de Mikhail Bakhtin (2011; 2013) e Raymond Williams (2011; 1979).

\section{PALAVRAS-CHAVE}

Amazônia. Imaginário social. Discurso.

O estereótipo, então, como ponto primário de subjetificação no discurso colonial, tanto para o colonizador como para o colonizado, é a cena de uma fantasia e defesa semelhantes - o desejo de uma originalidade que é de novo ameaçada pelas diferenças de raça, cor e cultura (Homi K. Bhabha, 2013, p. 130).

\section{INTRODUÇÃO}

"Dez anos no Amazonas (1897-1907): Memória de um sertanejo nordestino emigrado àquelas paragens em fins do século passado", livro publicado originalmente no ano de 1949, na cidade de João Pessoa/ Paraíba, teve sua segunda edição em 1984, na capital Brasília/Distrito Federal. Reúne ao longo das mais de 100 páginas as narrativas do paraibano Alfredo Lustosa Cabral (1883-1960), autor do referido livro.

De acordo com o prefaciador da primeira edição do livro, senador Jorge Kalume (PDS - AC), Alfredo Lustosa Cabral "soube ser ímpar como desbravador do noroeste do meu Estado, o Acre (...) sua figura será sempre relembrada com gratidão pelo povo acreano e pela nossa pátria” (CABRAL, 1984, n.p.), julgo afirmar, que a admiração do senador Jorge Kalume, caminha na mesma direção de Octacílio Nóbrega de Queiroz, prefaciador da segunda edição. Este ressaltou que a obra "se trata de um testemunho pessoal e escrito, quase único, talvez, espontaneidade singelo, mas duramente vivido, de um sertanejo-nordestino, atirado quando jovem, as terras e florestas amazono-acreana" (CABRAL, 1984, n.p.).

O paraibano Alfredo Lustosa Cabral, nasceu em 14 de janeiro de 1883, aos quatorze anos ficou órfão, sendo criado desde então por seus irmãos. Deslocou-se para a Amazônia ao ouvir as encantadoras e deslumbrantes histórias daquela terra, contadas por seu irmão recém chegado de lá, Silvino Lustosa Cabral. "Boquiaberto, ouvia estarrecido o desenrolar das narrativas" (CABRAL, 1984, n.p.). E acompanhado por este contador das histórias bonitas, fantásticas, bem como pela a ideia de facilidade de enriquecimento, os irmãos aprontaram para seguir viagem em setembro de 1987, com destino à Amazônia.

Parte das narrativas acontece nos seringais da Amazônia, ao curso ou sobre as barrancas dos rios afluentes do Juruá: Tarauacá, Moa, Tejo, Amoena e Muru. Nestes espaços em que vivenciou e permaneceu por dez anos, o autor contemplou as mais diversas culturas, resistências, crenças, linguagens e práticas sociais relatadas em suas narrativas. Descritas de forma marcante, seus escritos envolvem o leitor a cada página, bem como os dramas sentidos e vividos, fantasias, lendas e episódios pitoresco, que consagram o autor no rol dos demais pensadores amazonialistas.

Um livro que evidencia um determinado imaginário social e cultural da Amazônia.

1 Mestre em Letras pelo Programa de Pós-Graduação em Letras: Linguagem e Identidade da Universidade Federal do Acre e Professora da Educação Básica, vinculada à Secretaria de Estado e Educação do Acre. 
Imaginário este, visto primordialmente a partir das narrativas dos exploradores da região a partir do século XVI, quando a futura Amazônia foi vista como "caminho-cenário, o fio condutor das tramas narrativas elaboradas pelos cronistas, tanto do êxito quanto dos insucessos ocorridos aos descobridores/conquistadores ibéricos que percorreram a Amazônia nos séculos XVI e XVII” (UGARTE, 2009, p. 169).

De acordo com Auxiliomar Ugarte, o período entre 1530 e 1540 foi marcado pelas histórias sobre o El Dorado e o País da Canela, o que ocasionou a vinda dos irmãos Pizarro a estas terras. Gonzalo Pizarro e Francisco Pizarro tiveram contato com varias tribos indígena, "os conquistadores, para matar sua fome, recorriam ao saque das aldeias, nas quais encontravam alimentos em abundancia" (UGARTE, 2009, p. 41), iniciando assim diversos confrontos. O autor narra que em um desses conflitos, os irmãos tiveram a impressão de ter lutado com as lendárias Amaz̧onas, denominando o Rio Orellana, que já havia sido grafado como Rio Marañón, para Rio das Amazonas.

A veracidade ou não das narrativas dos cronistas não está em foco neste trabalho. A apropriação dos estudos de Auxiliomar Ugarte auxiliou no tocante à necessidade de explicitar que o mesmo discurso nos relatos de Alfredo Lustosa Cabral é enfatizado desde há muito tempo nas narrativas de viagem. Com o sentido de afirmar/reafirmar o discurso de "ocupação", de "vazio demográfico", no intuito de legitimar o discurso de "civilizar" o "não civilizado".

Esta Amazônia "desgraciosa e triste", marcada pela dicotomia inferno/paraíso cristalizada desde as primeiras trajetórias de Euclides da Cunha, em sua viagem pelo rio Purus no início do século XX, "sempre teve o dom de impressionar a civilização distante" (CUNHA, 1967, p. 20). As impressionantes paisagens da floresta amazônica, os vales fluviais, a cultura, as experiências e vivências são os personagens principais de diversos relatos científicos, históricos e literários.

Este espaço amazônico de homens, mulheres e crianças, produtores de culturas, resistências e práticas sociais e culturais, necessita do distanciamento da historiografia estereotipada por discursos e conceitos cristalizados. Recorrendo a Raymond Williams, pode-se compreender que "os conceitos, como se diz, dos quais partimos - não são conceitos, mas problemas, e não problemas analíticos, mas movimentos históricos ainda não definidos" (WILLIAMS, 1979, p.17).

Caminhando nesta direção que aponta Williams, em que os conceitos interagem com uma dada história e com as experiências em transformação (1979, p. 18), propomos neste trabalho uma reflexão sobre o "olhar" lançado a Amazônia e uma reinterpretação das memórias narradas por Alfredo Lustosa Cabral, ao longo destes dez anos na Amazônia.

A obra está organizada com vinte e cinco capítulos, onde o autor busca traçar um perfil socioeconômico e cultural da Amazônia do final do século XIX e início do século XX. No primeiro momento são narrados os episódios do deslocamento do próprio Alfredo Lustosa Cabral e seu irmão Silvino Lustosa Cabral. No segundo momento o autor relata as histórias e os causos vivenciado por ele no momento de sua estadia em "àquelas paragens". Na parte final do livro o autor apresenta o que ele julga de necessário e interessante para o leitor: são as observações e apenas alguns trechos de uma cantoria sobre a Amazônia, pois algumas estrofes foram perdidas pela memória desse memorialista nordestino.

\section{ENTRELAÇANDO NARRATIVAS}

A Amazônia pensada a partir destas construções discursivas, sempre foi caracterizada por um lugar inferior, estereótipo este que o autor faz referência nos episódios narrados por ele. O autor e personagem principal do livro relata seu deslocamento dramático para Amazônia nos navios "Pernambuco" e "Paraense". Com passagens compradas e aguardando somente a ordem de embarque, aguardaram ainda um dia no porto, para o despejo de passageiro e cargas do navio "Pernambuco".

Após a tamanha demora deste navio que veio como "lata de sardinha", foi embarcado 
as duas horas da tarde e "a muito custo localizamos nossas redes e bagagens por cima das malas dos passageiros, pois, não havia mais espaço nos porões do navio" (CABRAL, 1984, n.p.). No trajeto "vagaroso" e "agonizante" que não comportava mais um grilo, Alfredo relata um dos causos da viagem no navio "Pernambuco":

As redes armadas, duas, três, por cima das outras. Com a chegada desse povo a bordo, surgiu logo um pé de briga. Num recanto do porão, achavam-se armadas algumas redes pertencentes a um casal, com três mocinhas alegres, simpáticas. Um espertalhão achou de colocar a sua entre as das moças. O pai das meninas, ao ter conhecimento do caso, reagiu furioso. Saiu desaforo de parte a parte. Os vizinhos interviram a favor do pai das moças, e o atrevido capitulou, subiu o tombadilho do navio indo ajeitar sua rede por cima do garajau das galinhas (CABRAL, 1984, n.p.).

Com o anseio de livrar-se da sórdida embarcação, depois de muitas paradas para os embarques e desembarques, avistaram o belíssimo panorama da cidade e porto de Belém. Local em que se hospedaram no Hotel das duas Nações, que pertencia a portugueses e espanhóis, motivo pelo qual carregava o nome de "Duas Nações", aguardando a saída do navio "Paraense", que havia de viajar em novembro rumo ao alto Juruá. Fica deslumbrado as impressionantes paisagens e um encanto pela dimensão do rio Solimões em que "os pássaros de vôo curto como tucano, o mutum, o jacu, o jacamin, o cojubim caem n'água ao tentarem vadear o fabuloso rio. Uma pessoa na margem oposta torna-se invisível" (CABRAL, 1984, n.p.).

No período em que Alfredo Lustosa Cabral esteve na Amazônia, o autor exerceu várias funções, como carpinteiro, cozinheiro, regatão, agricultor, inspetor de quarteirão e vendedor. $\mathrm{Na}$ passagem do capítulo VI, o autor narra um período de sua vida, que viveu sob as ordens do patrão Sr. João Marques de Oliveira, dono do seringal Nova Esperança:

Eu trabalhava na venda do barracão, pesando café, açúcar, arroz, e tudo mais para os seringueiros,
especialmente no domingo, quando eles chegavam do centro. Desejei tirar borracha ao lado dos
seringueiros. Meu irmão consentiu que fosse. Fui morar numa barraca, a duas horas de viagem, a
margem de um lago imenso, bem piscoso, cheio de jacarés e supostas morada de grande sucuruju.
Em companhia de dois seringueiros "mansos" estive dois meses, apenas. Tinha o nome de "brabos"
os que chegavam ali pela primeira vez. Acordava-se às quatro horas da manhã, para se cuidar do café
e do almoço, ainda com escuro. Cada um seguia sua estrada com machadinho de três centímetros
de largura, golpeando as seringueiras e embutindo as tijelinhas de flandre abaixo do golpe. Conduzia
mais a escopeta, um terçado embainhado a cinta e uma estopa atada nas quatro pontas, a tiracolo,
para as caças que matava. No trabalho da estrada deparava-se sempre com o itapuru cantando. Para-
va para ouví-lo. Chegava para bem perto a fim de conhecê-lo (...). Às dez horas estávamos na barra-
ca. Fazia-se uma ligeira refeição para voltar novamente à estrada e juntar o látex. Chagávamos quase
sempre as três da tarde. Íamos para o defumador preparar a borracha. O leite coagulava-se rápido ao
ser levado à fumaça quente de boião de ferro, com formato de funil de meio metro de altura, dentro
de uma casinha de palha (o defumador) adequada àquele trabalho (CABRAL, 1984, n.p.).

Vale ressaltar, mais uma vez, que essas construções discursivas estereotipadas, presente em grande parte das falas do autor e reproduzidas e repetidas constantemente em relatos históricos, científicos e literários, justifica-se de acordo com Mikhail Bakhtin, pois "cada texto (como enunciado) é algo individual, único e singular, e nisso reside todo o seu sentido (sua intenção em prol da qual ele foi criado)" (2011, p. 310).

O sentido de decodificação dos signos de repetição/reprodução constante na obra, que corresponde ao que Bakhtin expressa, que "todo sistema de signo (isto é, qualquer língua), por mais que sua convenção se apoie em uma coletividade estreita, em princípio sempre pode ser decodificada, isto é, traduzido para outros sistemas de signos (outras linguagens)" (2011, p. 311). Evidentemente, não se pode pensar em uma linguagem única, nem mesmo centrada por uma veracidade concreta.

Alfredo Lustosa Cabral e seu irmão Silvino Lustosa, com pretensão de explorar seringais com uma maior produção de leite, deixaram o Nova Esperança, com destino à foz do Tejo: 
Quando entrei, não achei lugar para armar a rede. Navio pequeno, com 300 passageiros de prova, todos doentes de sarampo e dissentiria. A muito custo, e com o auxílio do marinheiro, que me embarcou, atei a rede a um canto. Perguntou-me se já tinha tido sarampo. - Não sei, respondi. - Não levam remédio para essa gente? Perguntei. - Qual remédio amigo. Aqui não tem nada, nem remédio, nem farmacêutico a quem recorrer. Estão se acabando à míngua. Só se ouvia gemidos e gritos lancinantes, que saiam das redes infectadas. $\mathrm{O}$ dia amanhecera. $\mathrm{O}$ navio encostou num certo porto para desembarcar dois que haviam falecido àquela noite. A imundície era pior do que a dos porões do "Pernambuco". Chegamos, afinal, à boca do Tejo, depois de uns poucos dias de viagem cheia de tormenta. Metade dos passageiros desembarcou em braços para enfermarias improvisadas que arranjaram numas barracas da palhas, desabrigadas, próximas ao barracão. Dei graças a Deus ter chegado vivo contando a história (CABRAL, 1984, n.p.).

Chegado ao destino, os dois irmãos fizeram barracas a mando do novo patrão ao lado dos índios, estes que por sinal amedrontava-os imitando os cantos dos pássaros. Cerca de aproximadamente de 200 homens trabalhavam nas redondezas do Tejo, localidade na qual Alfredo Lustosa e seu irmão permanecerem por um curto período.

A presença feminina marcada de forma acentuada nas narrativas aparece nos escritos de Alfredo Lustosa Cabral a partir do capítulo IX, momento em que o autor relata com estilo pitoresco a sua passagem pela a boca do Moa, afluente do Juruá, descrevendo o período em que foi "caixeiro-vassoura", tendo como patrão um velho de mais de sessenta anos, violento e mal-humorado, que fora capitão exército, abandonando o cargo para cultivo exclusivo da cultura da borracha:

Brigava muito com a mulher. Numa sexta-feira da Paixão, surrou-a por três vezes a espadim. A mulher criava uma galinha, e estas danaram-se a gritar nesse dia. O velho aborreceu-se e mandou um sujeito espingardeá-las. Quando esse indivíduo já tinha morto umas quinzes, a velha partiu irada para tomar a espingarda, e nisso o velho gritou: Passe fogo nesse diabo... O rapaz não obedeceu a ordem, nem era doido para isso. $\mathrm{O}$ velho mandou juntar as galinhas e jogá-las no rio. Não deixou ninguém as aproveitar (CABRAL, 1984, n.p.).

Contradizendo sua própria fala do capítulo XII, “ali não existia mulher elemento esse indispensável em toda parte" (CABRAL, 1984, n.p.), a figura da mulher aparece em diversas passagens no seu texto. No capítulo XVI, o autor narra a história de um casal, D. Júlia e seu marido (cujo o nome não é revelado). Segundo o autor, o seringueiro marido de D. Júlia era um doente de "ferida braba" que havia trabalhado por um bom período no Seringal São Raimundo, localizado no riozinho da Liberdade.

O Seringal São Raimundo pertencia a Antônio Barroso, este, não satisfeito com a atual situação do marido de D. Júlia, fez uma proposta ao cearense Paulino de Azevedo, que era um "trabalhador, econômico, conseguiu acumular no Contas Correntes do patrão sua meia dúzia ou mais de contos de réis, crédito era só quem tinha" (CABRAL, 1984, n.p.). Pensando no bem do seringueiro e mais no seu próprio, o patrão propôs a este que pagasse a conta do doente e por recompensa ganharia a D. Júlia, que segundo o autor tinha as suas virtudes.

Após um curto momento de reflexão, por quatro contos, Paulino fez negócio com o patrão. E se tornara o novo noivo do Seringal São Raimundo. No entanto, o desfecho da história terminou tragicamente:

A meia-noite, Paulino desceu com D. Júlia a escada do barracão e foi visitar a fogueira que estava prestes a terminar. Ali palestravam sobre a nova vida que iriam encetar dessa noite em diante, de frente um para o outro receberam de chofre um formidável tiro de bacamarte pelas costas, que os deitou por terra. Caíram abraçados na beira da fogueira. Do barracão da festa ouviram o tiro e a queda dos noivos. Correram todos as pressas para o local do sinistro, encontrando-os bem feridos. Paulino recebera trinta e tantos bagos de chumbo e D. Júlia três apenas. Foram feitas rigorosas investigações sobre o crime. É que o legítimo marido, ao deparar os noivos ao clarão da fogueira confabulando, irou-se, arranjou um bacamarte velho, carregou-o e mando-lhes o tiro de misericórdia na certeza de exterminá-los de uma vez. Encostou a velha arma detrás de uma porta e deitou-se, embrulhado no lençol como se nada houvesse acontecido. A festa acabou-se. Todos corriam a socorrer os feridos enquanto uns conseguiam saber que o assassino era o desventurado marido de D. Júlia. 
No dia seguinte, Antônio Barroso mandou levar em canoa o criminoso a foz de rio Mu, que dali seguiria para sua terra. Os noivos escaparam, mas tiveram de passar mais de três meses acamados sem poder dar agua um ao outro (CABRAL, 1984, n.p.).

Apesar do final cômico relatado por Alfredo Lustosa, em que expressa a fala de Bakhtin, o "aspecto burlador e denegridor estava profundamente associado ao riso" (2013, p. 65). A historiografia amazônica é caracteriza pela assertiva da ausência da figura feminina em seus relatos. Quando há a presença da mulher nos seringais, em grande parte, ela é direcionada a mulher comercializada como mercadoria, ou mesmo utilizada como recompensa. O autor conta que diante de tais especificidades:

\begin{abstract}
Não é de todo dispensável dizer, aqui, que eram muito difíceis, naquela época, as relações entre os dois sexos. Regiões havia, numa extensão de dez a doze propriedade, onde não se encontrava uma dona-de-casa. A aquisição de uma donzela da selva era tarefa temerária, porque raramente a índia se sujeitava ao regime doméstico. Isso ainda podia acarretar o perigo de ser a moça levada pelos da tribo ou haver choques violentos, da parte a parte, transformando-se em intriga que não se acabaria mais. Sob esse aspecto, as uniões de seringueiros com selvagens eram quase nulas. Foi por isso, atendendo a tamanha irregularidade de vida, que certa ocasião, a polícia de Manaus, de ordem do Governador do Estado, fez requisição nos hotéis e cabarés dali de umas centos e cinquenta rameiras. Com tão estranha carga, encheu-se um navio cuja missão foi a de soltar, de distribuir as mulheres em Cruzeiro do Sul, no Alto Juruá. Houve, dessarte, um dia de festa - a de maior pompa, que se tinha visto. Amigaram-se todas não faltou pretendente. Contudo, umas não se deram com o clima, adoeceram e morreram. Outras conseguiram voltar a Manaus e, muitas, por fim, foram mais felizes... É que, mais tarde, apareceu um sacerdote e as casou (CABRAL, 1984, n.p.).
\end{abstract}

Em fevereiro de 1902, Alfredo Lustosa Cabral partiu para o Seringal Redenção, com a notícia de vantagens no lugar e com pretensão de encontrar um local produtivo. Na madrugada dirigiu até o batelão que ia de viagem para o alto Tarauacá, ao encontro de seu irmão Silvino que teria ido à frente. Apesar da fartura de seringueira, por ser um seringal novo, os 48 homens que viviam no local estavam, segundo Alfredo, em situações precárias:

Estávamos em redenção mal alimentados (...) raramente abatia-se um porco, anta ou mutum. Muitas
vezes nos alegrávamos ao encontrar nos paus altíssimos um guariba, coatá ou barrigudo. Cortava-
se logo a palma da mão da caça par saber se estava gorda, enxuta pelo menos. Tirava-se o couro
levando-a à panela, temperada com pimenta do reino e banha, quando havia. Passava-se necessidade,
fome, pela falta de caças e peixe naquele rio. O seringueiro chega sempre do trabalho da estrada
fatigado sem encontrar o que comer. Prepara logo chibé, alimentação rápida feita com um pouco de
farinha, açúcar e agua bem mexidos. Estava pronto o lanche para enganar o estômago (CABRAL,
1984, n.p.).

Havendo a necessidade de providenciar alimentos, chegando a Tarauacá, trataram de fazer um roçado com ajuda dos demais trabalhadores, com a plantação de mandioca, milho, cana, e banana, "nos dias de segunda e terça, preparava-se farinha: quarta e quinta colhia-se o feijão, que era batido. A sexta e sábado eram reservados à moagem, conseguindo-se de cem a cento e cinquenta quilos de rapadura" (CABRAL, 1984, n.p.). Assim, conta Alfredo, que no domingo era o dia em que os demais trabalhadores vinham do centro e o que era produzido durante a semana era compartilhado com todos.

Permaneceram neste trabalho de julho a novembro, quando Alfredo, Silvino e outros três desceram à foz do rio Murú, a procura de mais produtos e mercadorias. No entanto, na metade da viagem, Alfredo voltou ao seringal Redenção para socorrer os demais trabalhadores:

Ali arranjou-se uma canoa possante e fui eu escalado para voltar. À tarde, carregamo-la com seis paneiros de farinha, banha, querosene, arroz, balas, uns quatrocentos quilo de carga ao todo. Pela manhã, os companheiros desciam para a boca do Muru, enquanto eu subia só tangendo a canoa a varejão em busca do Redenção. Ao meio-dia, encostei a canoa, e debaixo de uma sombra amiga fiz o fogo, esquentei uma lata de sardinha e comi. Feita a refeição, segui viagem. As cinco horas da tarde, deparei com um roçado tendo no centro uma barraca. Notei que estava deserta, não havia fumaça nem gente. Passei ao largo a fim de ver se conseguia outra morada perto. Não fiquei ali temendo dormir só. Quando transpus duas voltas, o sol desaparecia no ocaso. Escureceu. Não tinha mais o que tentar nem pra cima nem pra baixo. O rio entulhado de paus corria perigo de naufrágio. (CABRAL, 1984, n.p.). 
Depois de cinco dias, Alfredo chegou ao seringal Redenção. Recebido com a notícia que os índios catuquinas, que moravam aproximadamente à dez horas de viagem, do outro lado do rio, haviam atacado a barraca de um seringueiro do seringal Lugar Primavera, "mataram três pessoas e roubaram o que haviam encontrado" (CABRAL, 1984, n.p.).

Apesar do cotidiano conflituoso, o autor relata as histórias de entretenimento, diversões e alegrias. Em noites de São João era uma alegria só, todos reunidos, dançavam, bebiam e festejavam pelo dia. Alguns ficavam responsáveis pela caça e comida, e outros pelo preparo da fogueira. Esse era somente o início da festa, que terminaria bem cedo, momento em que os seringueiros iam até o rio, se banhar com a água considerada benta.

Alfredo Lustosa conta que sete mulheres haviam sustentado a festa, em um animoso ritmo, tratava de "quatro mulheres bem maduras na idade e três em estado interessante muito adiantado" (CABRAL, 1984, n.p.). A diversão tornava-se completa com a figura de "Judas", que fora também relatado no livro "A margem da história”, de Euclides da Cunha, "o judas faz-se como se fêz sempre: um par de calças e uma camisa velha, grosseiramente cosidos, cheios de palhiças e mulambos; braços horizontais, abertos, e pernas em ângulo, sem juntas, sem relevos, sem dobras, aprumando-se, espantadamente, empalado, no centro do terreiro" (CUNHA, 1967, pp. 74-75). Alfredo Lustosa Cabral relata que a figura de Judas, constituía a mais interessante diversão:

Na sexta-feira da Semana Santa, prepara-se o intruso vestido de roupas velhas, modelando-o com
detalhes precisos. Bem cedo é colocado em balsa, quase sempre de bananeira, e sobe-se com ele
até a primeira volta de rio. Larga-se no meio d'agua e volta-se ligeiro ao porto. Já alguns rifles estão
ali de prontidão para crivá-lo de balas. Desce levado pela correnteza recebendo descargas inteiras
até encobrir-se na volta abaixo. Mais tarde vem outro e mais outros nos dias seguintes, todos re-
cepcionados a bala ao serem divulgados. O seringueiro gasta grande quantidade de munições nesse
divertimento ingênuo e imbecil detonando caixas e mais caixas de balas Winchester em prejuízo de
seu bolso (CABRAL, 1984, n.p.).

A literatura tem um influente papel na difusão do discurso estereotipado de uma certa "brasilidade", procurando afirmar "por meio da diversidade, ou seja, pela manutenção das diferenças peculiares de tipos e personagens; por paisagens sociais e históricas de cada área do país, reduzindo a nação a um simples somatório dessas especialidades literárias diversas" (ALBUQUERQUE JUNIOR, 2011, p. 65-66). No que se refere a "tipos" e "personagens" tipicamente brasileiros, a caricatura de "Jeca Tatu", torna-se muito conhecida como representação do "tipo" brasileiro do mundo rural brasileiro no século XX.

No livro Um sertão chamado Brasil: intelectuais e representação geográfica da identidade nacional (1999), de Nísia Trindade Lima, esta autora faz alguns apontamentos no direcionamento da "identidade brasileira", tendo como referência a imagem de "Jeca Tatu". Emerge daí a caracterização de um homem "doente", "preguiçoso", "indolente", "caipira", vista nos contos de Monteiro Lobato, reforçando o polêmico discurso de uma "identidade" do homem brasileiro.

Neste contexto, como observou Nísia Trindade, pode-se afirmar que esta construção de uma "identidade" nacional, pautada em aspectos desarticulados do "real" vivido, intenciona o discurso em torno da representação social/cultural da sociedade, tendo o "pensamento social brasileiro como imagens de grande força simbólica, que expressam os contrastes e, no limite, o antagonismo de distintas formas de organização social e cultural” (LIMA, 1999, p. 22).

No que tange os aspectos do decantado atraso cultural/social da nação, temos instituído um duradouro estereótipo de "identidade" nacional. Para Homi K. Bhabha o estereótipo não é uma falsa representação do real, "é uma simplificação porque é uma forma presa, fixa, de representação que, ao negar o jogo da diferença (que a negação através do Outro permite), constitui um problema para a representação do sujeito em significações de relações psíquicas e sociais” (2013, p. 130). 
Ainda narrando às histórias do Seringal Redenção, Alfredo Lustosa apresenta a "identidade" típica do cearense, aquele homem "trabalhador", "macho", "cabeça-chata". O autor fala que no Redenção, os 48 seringueiros eram conhecidos por apelidos, de acordo com as suas características e sua naturalidade:

Em Redenção, viviam quarenta e oito homens. Destes, quatro paraibanos, “cabeças de coco" (meus irmão, proprietários do seringal, eu e o moleque João, daqui de Patos), um pernambucano - "ladrão de cavalo", dois rio-grandenses do norte - "cusrajados", um piauiense - "espiga", um maranhense - "maranhoto". Quando ao paraense, não estou lembrado de seu apelido. O mineiro que raramente, aparecia ali, era tido como "falso e traiçoeiro". Ao criar-se, em 1904 (julgo), o Departamento do Alto Juruá, foi o general Gregório Thaumaturgo de Azevedo nomeado prefeito da cidade de Cruzeiro do Sul, colocada à foz do rio Moa. Os cearenses diziam, então, ironicamente: "Estamos de sorte, vamos agora ser governados por um "espiga” do Piauí (CABRAL, 1984, n.p.).

Outra "personagem” destacada em Dez anos no Amazonas é a figura do indígena, representado nas muitas etnias que viviam nas cabeceiras dos afluentes do Alto Juruá. O autor cita as tribos Catuquina, Caxinauá, Jaminauá, Culina e outras, que tinham um “dialeto” bem próximo uma das outras, segundo o autor, o índio "é de índole preguiçosa e indolente, desconfiado e ciumento, quem for a uma aldeia não faça motejo, todo cuidado é pouco” (CABRAL, 1984, n.p.).

No capítulo XVIII, o autor passa a contar algumas histórias sobre superstições, mitos e lendas da Amazônia. Muitas delas contadas pelos os seringueiros que afirmavam com propriedade a existência e veracidade dos fatos. Destacam-se as histórias de curupira, caboclinho, boto vermelho, matintapereira, uirapuru, mapinguari e sucuruju, esta foi narrado da seguinte maneira:

\begin{abstract}
A sucuruju é, nas lendas, também conhecida por boiúna: Aparece, vez por outras, fazendo alarmes pelo rio às caladas das noites escuras, fingindo uma embarcação em movimento, com seus faróis nitidamente acesos. De um momento para o outro, desaparece, causando por esse motivo terror aos que a vêm. Outras vezes, transforma-se em rapaz esbelto, simpático e alegre nos bailes e festas noturnas. Antes de o relógio marcar meia-noite, desaparece sem ser pressentido. Dizem que num seringal do baixo Juruá compareceu em festa um desses tipos. Entreteve-se dançando algumas horas e, quando se lembrou de sair, o relógio já havia ultrapassado das doze horas. Irriquieto, num pé e noutro, ficou sem mais poder sair do barracão. Pediu ao dono da casa que lhe arranjasse um quarto, pois se achava bastante incomodado. O chefe determinou um apartamento reservado, onde o rapaz se agasalhou. As danças continuaram até o dia claro e a festa quase terminada. O chefe do seringal tratou de acordar o hospede e que surpresa não teve ao abrir da porta! O quarto estava cheio de uma cobra, uma serpente enorme, que, ao ver o clarão do dia, desenrolava-se deslizando a superfície soalhada do salão da festa, seguia à porta de frente em procura do rio, enquanto o povo corria espavorido, as tontas de medo, afastando-se do monstruoso ofídio (CABRAL, 1984, n.p.).
\end{abstract}

No início de 1907, Alfredo Lustosa Cabral, deixou Tarauacá com destino a sua terra natal. Deslocou-se no navio "Manauense", que chegara ao porto do Redenção em janeiro. Com dois dias de viagem estavam na foz do Muru, local que permaneceram por uma noite. Havia uma festa em comemoração a inauguração da Vila Seabra (hoje Tarauacá), “achavam-se presentes todas as autoridades - juiz, promotor, tabelião, delegado, agentes do fisco, assistimos à festa, ouvindo discursos, vivas, apitos, de navios e espocar de garrafas." (CABRAL, 1984, n.p.). Passado pelo à foz do Tarauacá, do Juruá, do Solimões, do Manacapuru e do rio Negro, Alfredo Lustosa, finalmente chegou em Manaus.

Em Manaus, Alfredo permaneceu por doze dias hospedado na "Pensão 31 de Janeiro". Neste período frequentou o "Café Itatiaia", que seria na época um dos melhores lugares da capital amazonense, frequentado somente por elites da cidade. O Teatro Amazonas é lembrado, mas o cabaré El-Dorado é considerado por ele um ambicionado tesouro, que viera conhecer nos últimos dias de sua passagem no Amazonas:

A mais luxuosa pensão, o mais empolgante cabaré da América do Sul. Fortemente iluminado, com todas as sortes de jogos, com teatro, era lugar de lindos rostos de todas as partes do mundo - polonesas, francesas, portuguesas, peruanas, brasileiras dos vinte e um Estados, todas, enfim, ali se 
exibiam numa libertinagem desordenada, doida. Escravizado oito ou dez anos na selva, sem relações com o sexo oposto, o seringueiro que chegava à cidade, não o deixava de frequentar. A exploração era roxa. Muitos ali deixavam todo dinheiro que haviam arranjado com enormes sacrifícios. "lisos" - restava-lhes ir ao escritório do patrão implorar uma passagem no gaiola e retornar ao seringal de onde saíram (CABRAL, 1984, n.p.).

Com destino à Fortaleza (Ceará), embarcou no paquete "Maranhão", que segundo o autor, foi utilizado pelo Presidente Afonso Pena, em uma visita as capitais da Região Norte havia pouco tempo. Em Fortaleza hospedou-se em uma República, que seu primo (acadêmico de Direito), era responsável, residindo com seis bacharelandos. Após dias de viagem no navio "Espirito Santo", Alfredo Lustosa Cabral, retornou ao Sul:

Nesse dia a A União estampara em seu noticiário: "Pelo vapor "Espirito Santo", chegaram a nossa capital, vindos de Fortaleza, os acadêmicos de Direito Francisco Falcão, Paulo Pedro Montenegro, Alfredo Lustosa Cabral e Américo Falcão.” Vinham conosco também outros estudantes, de que não me recordo os nomes (...) Fui recebido com estrepitosa alegria. - Dez anos vividos ausentes dos meus... no Amazonas (CABRAL, 1984, n.p.).

De acordo com o prefaciador Octacílio Nóbrega de Queiroz, após os dez anos no Amazonas, o autor Alfredo Lustosa Cabral foi professor primário por vinte anos e aposentou-se pelo magistério público. Em seguida formou-se em odontologia pela Faculdade de Medicina e Odontologia do Recife, exercendo a função de cirurgião-dentista, quando passou a se chamar Dr. Alfredo Lustosa Cabral. Faleceu em 31 de dezembro de 1960.

Ainda sobre a obra, o autor reserva as ultimas páginas a um aglomerado de informações, que considera de grande importância. Sob o título, "Notas do autor", Alfredo Lustosa apresenta pequenas observações sobre sua permanecia na Amazônia. As notas especificam em detalhes questões sobre a "piracema (festa dos peixes)", "utensílios de pesca”, "trabalhos e alimentação", "agricultura”, "saúde”, "policiamento”, "estrangeiros”, “caiçuma”, "Catuquinas e Caxinauás”. Da língua desses indígenas, o autor apresenta um pequeno dicionário:

Homem civilizado - Cariú; Mulher - Cunhã; Moça - Cunhatã; Menino - Colomi; Camisa - Fari Suti; Calça - Tari Quixi; Meias - Taritai; Rede - Tari pane; Rede de cipó - Maqueira; Fazendas - Tari; Orelha - Pavinquim; Braço - Suti; Pernas - Quixi; Pés - Tai; Milho - Chuqui; Macaxeira - Mani; Mamão - Chupá; Cana - Tauatá; Galinha - Tacará; Jacu - pucacunga; Mutum - Assim; Anta - Auá; Cachorro - Camã; Camelião - Xixupani; Vamos - Cauê; Vamos embora - Uri cauê; Tomar banho Daxitão; Espingarda - Mucáua; Comer - Mumahú; Ruim - Estapá; Doente - Manauana; Não quero - Timaã; Não presta - Pixueira; Negro - Tapaiúna (CABRAL, 1984, n.p.).

Ainda sobre a parte final da obra, Alfredo Lustosa, a título de "curiosidade" transcreve algumas estrofes de uma canção do compositor Silvino Pirauá de Lima, composta por vinte e quatro estrofes com informações sobre os rios, peixes, bichos, aves, e arvores da Amazônia. A canção termina da seguinte maneira:

Do Amazonas, senhores

As condições dizem tudo.

Lá só irá podre besta

Ou por outra cabeçudo,

Iluda-se lá quem quiser

Que eu mesmo cá não me iludo.

Silvino Pirauá de Lima

Chamado - o Paraibano,

Compositor desta obra,

Espera em Deus Soberano

Nunca ir ao Amazonas

Nunca ir ao Amazonas

Nem Deus lhe dar este plano. 


\title{
CONSIDERAÇÕES FINAIS
}

À medida que o autor relata suas histórias, causos, vivências e experiências, o discurso de um lugar "inferior", "vazio" e "não civilizado", que deve ser "temido" por todos, bem expressado na canção de Silvino Pirauá de Lima, citada pelo autor, brota exatamente tal como está posto e materializado na historiografia tradicional. Estas representações produzidas/reproduzidas pelos escritos históricos, bem como escritos literários e científicos, têm a intenção de se concretizarem como "elementos comunicantes no processo de formação de imagens, projetos e interpretações do Brasil” (MURARI, 2009, p. 35).

Alfredo Lustosa Cabral, traça ao longo das narrativas, um perfil socioeconômico e cultural da Amazônia e dos habitantes que ali viveram. O espaço amazônico caracterizado pelo o "olhar" do autor, não muito diverge dos escritos de Euclides da Cunha, instituindo, assim, um imaginário amazônico. Diante do exposto, queremos compartilhar o expressivo pensamento de Raymond Williams "o que sobrevive é uma experiência, um tipo de aprendizado específico; a escrita é importante apenas até o ponto em que ela transmite essa ideia. Ela é, finalmente, uma experiência pessoal que passa a ser um marco divisório" (WILLIAMS, 2011, p. 27).

\section{DEZ ANOS NO AMAZONAS (1897-1907): A SOCIAL IMAGERY ON AMAZONIA}

\begin{abstract}
The main topic of the article "Dez anos no Amazonas (1897-1907): a social imagery on Amazonia" is the analysis of Alfredo Lustosa Cabral's story narrated in "Dez anos no Amazonas (1897-1907): Memória de um sertanejo nordestino emigrado àquelas paragens em fins do século passado". The main objective is a reinterpretation of the social imagery of Amazonia narrated by Alfredo Lustosa Cabral - who lived ten years in a rubber tree plantation of the area - on the basis of Discourse Analysis. As theoretical basis, Mikhail Bakhtin's (2011; 2013) and Raymond Williams's (2011; 1979) works will be used.
\end{abstract}

\section{KEYWORDS}

Amazonia. Social imagery. Discourse.

\section{REFERÊNCIAS}

ALBUQUERQUE JUNIOR, D. M. A invenção do nordeste e outras artes. $5^{a}$ edição, São Paulo: Cortez, 2011. BHABHA, H. K. O Local da Cultura. Trad. Myriam Ávila, Eliana Lourenço de Lima Reis, Glaúcia Renate Gonçalves. $2^{a}$ edição, Belo Horizonte: Editora UFMG, 2013.

BAKHTIN, M. A cultura popular na Idade Média e no Renascimento: O contexto de François Rabelais. Trad. Yara Frateschi Viera. São Paulo: Hucitec, 2013.

BAKHTIN, M. Estética da criação verbal. Trad. Paulo Bezerra. São Paulo: Martins Fontes, 2011.

CABRAL, A. L. Dez anos no Amazonas (1897-1907): memória de um sertanejo nordestino emigrado àquelas paragens em fins do século passado. 2. ed., Brasília: Senado Federal, 1984.

CUNHA, E. À margem da história. Rio de Janeiro: Lello Brasileira, 1967.

LIMA, N. T. Um sertão chamado Brasil: intelectuais e representação geográfica da identidade nacional. Rio de Janeiro: Revan, 1999.

MURARI, L. Natureza e cultura no Brasil. São Paulo: Alameda, 2009.

UGARTE, A. S. Sertões de bárbaros: o mundo natural e as sociedades indígenas na Amazônia na visão dos cronistas ibéricos - séculos XVI/XVII. Manaus: Valer, 2009.

WILLIAMS, R. Cultura e sociedade: de Coleridge a Orwell. Tradução de Vera Joscelyne. Petrópolis (RJ): Vozes, 2011.

WILLIAMS, R. Marxismo e literatura. Tradução de Waltensir Dutra. Rio de Janeiro: Zahar, 1979.

Data de recebimento: 20/01/2016

Data de aceite: $14 / 03 / 2016$ 